\title{
The Study of English Micro Class Overturning Classroom Teaching
}

\author{
Jinzhong Liu', Nan Li, Yang Liu, Di Yan, Jingjing Guan, Xueyan Sun \\ Foreign Language Department, Qiqihar Medical University, Qiqihar 161006, China \\ aliujinzhong@126.com
}

Keywords: micro class, flipping class, knowledge imparting, internalization of knowledge

\begin{abstract}
The flipped classroom has caused our teachers concern and attention; China has a number of schools as teaching reform, began to explore the flipped classroom teaching practice, and achieved good teaching effect, such as the Chongqing Jukui school, experimental high school, Shenzhen Nanshan Mountain in Dongchang. However, there are few research and Practice on the English flipping classroom teaching mode, and the research on the application of the English reversal classroom teaching mode based on the micro class is very few. Micro lesson has attracted numerous scholars and attention to the importance of implementing flip classroom teaching, micro course is the foundation of the flipped classroom, the flipped classroom is micro carrier class development. Based on the analysis of the relationship between flipped classroom and micro lesson, this paper designs a teaching flow chart of English flip classroom based on micro lesson, and takes English practical writing as an example to illustrate how to implement flipped classroom teaching based on micro lesson.
\end{abstract}

\section{Introduction}

In the past two years, a new video teaching model "micro class" has become a hot phenomenon in the field of educational research and application in China. Some scholars who devoted themselves to the research of flipped classroom also realized the important role of micro lesson in implementing flipped classroom teaching, such as Guo Shaoqing, Yang Bin, Wang Qiuyue, Liu Rui, Wang Haiyan, Lu Haiyan and others. The rapid development of the economy and the continuous progress of science and technology have put forward new requirements for the teaching of College English. The traditional teaching model is being impacted and challenged by new technology and new ideas.

With the wide application and rapid development of Internet technology, the teaching idea of "flipped classroom", which is conducive to cultivating students' autonomous learning ability, has been popularized and promoted. "Flip the classroom, is before class will advance design of video teaching to the students, the use of spare time by watching the video to learn new knowledge it contains, in the classroom teacher under the guidance of common work, solve questions, sharing and innovative collaborative inquiry teaching pattern." "Flipping" can not only refer to the transposition of the teaching process, but also the transformation of the teaching place.

In short, the "flipping classroom" has realized the flexibility of teaching in time, place and way. The emergence and application of flipped classroom teaching mode means that the advantages of the new teaching mode is more and more recognized by teachers and students. Compared with the traditional teaching mode, the "flip classroom" based on micro class can meet the needs of students' autonomous learning, and exercise can cultivate students' initiative and independent problems, and solve problems. Based on the micro course of flipping the classroom teaching content will break up the whole into parts, to simplify, has the characteristics of diversity, clear theme, vivid, compact structure etc.. In this teaching mode, students mainly finish knowledge learning through extracurricular activities, and digest and consolidate their knowledge under the guidance of teachers, improving their learning effect and ability. It is undeniable that the "turn over the classroom" optimizes the teacher's teaching mode and the student's learning pattern. 


\section{The Relationship between the Flipped Class and the Micro Class}

Flipped classroom is a form of teaching organization that inverts knowledge imparting and internalization of knowledge. Students are self-taught by watching videos recorded by teachers outside class. As we all know, there are not many students' extracurricular time, except the time of eating, rest and entertainment, the rest time is three or four hours, and we need to complete many courses' learning tasks.

If a course of teaching video time is too long, it is bound to cause great pressure on the students. It is a small micro class teaching organization form is very suitable for extracurricular self-study. Micro lesson refining, the students can easily grasp the learning objectives, improve the learning efficiency; micro class time is short, the students watching the process without fatigue, probability of the distraction of the lower class; micro convenient view, students can use any mobile multimedia devices, such as mobile phone, computer, watch the micro class rich content whenever and wherever possible. Include text, pictures and even movies, students can learn new knowledge in a relaxed atmosphere, reduce the pressure of study. As an important part of the flipped classroom, micro class directly decides the effect of knowledge transfer before class, and affects the design of classroom teaching activities, thus affecting the final teaching effect.

At present, the micro lesson is still in the construction stage, and the scope and intensity of the promotion are not enough. It is mainly applied to the exchange, learning, observation and learning among different teachers or schools, which is not inspiring and helpful to students, and the efficiency is not ideal. The extension and application of the overturned class will inevitably promote the rapid development of the micro class.

Some schools have begun to implement the flipping classroom teaching model, and have achieved good teaching results. The trend of overturning the classroom is very optimistic. In this case, the micro class rooted in the flipped class can also give full play to its advantages and be accepted and used by teachers and students. The teaching effect of the micro class can also be verified by overturning the classroom. The implementation of flip the classroom, students will meet after class learning problems in the process of feedback to teachers, collate and evaluate the students feedback, teachers will find deficiencies in micro class production, so as to promote the timely correction, micro class of continuous improvement.

\section{The Application Design of Flipped Class Based on Micro Class in English Teaching}

Flipped classroom is the subversion of traditional classroom teaching. The main purpose is to change students' passive learning situation, let students take the initiative to participate in learning activities, become the main body of classroom teaching, and further improve students' autonomous learning ability and learning efficiency. This requires teachers to design students as the center when designing teaching links, and create opportunities to cultivate students' ability to find and think problems and solve problems independently. Teachers should avoid teaching video as a disguised and instilled teaching. Besides video content, we should set up questions, thinking and practice links, so that students can not only listen and record in extracurricular learning process, but also solve problems and digest new knowledge through positive thinking and positive actions. In the classroom, the teacher is no longer the leader, no longer long lectures, but as the organizer and coordinator of the classroom activities. All learning tasks depend on students' ability or group cooperation. Teachers only give guidance and help when learning activities are not progressing well or students help.

Teaching feedback is an essential part of the teaching process. According to the feedback information, teachers make an analysis and judgment of the whole state of teaching activities, as well as the necessary correction and adjustment. According to the feedback information about their students' learning behavior and effect from teachers, their learning activities form reflection summary, and timely revise and adjust the learning behavior and their own way, make oneself in a normal and positive state in teaching. There are more opportunities for teachers and students to communicate in the flipped class than in the traditional class, so teachers can get feedback in a 
variety of ways. One is online communication through the network.

The students ask questions or suggestions to teachers through the communication platform. Teachers guide students' learning behavior and adjust their instructional design according to students' questions. Two is through the classroom face-to-face communication. In the course of the class, the students can ask for help to the teachers at any time. The teachers answer the problems for the students and understand their learning status and progress. The three is to get feedback through the correction operation. The teacher corrects the students' homework and writes the comments, and the students correct their shortcomings according to the teacher's comments.

\section{The Teaching Process of the Flipped Class Based on Micro Class}

Based on the analysis of research results at home and abroad, combined with the characteristics of English teaching, the author designed a flow chart of flip classroom teaching which is suitable for English classroom teaching. 3. flipped classroom teaching design based on the micro class. Taking the "invitation letter of English application writing" as an example, this paper expounds how to implement the flipping classroom teaching based on micro class in English teaching. In the process of recording micro class, whether it is the language of teachers or in the course of micro letter should try to use English, uncommon words can explain with Chinese.

This will help to exercise students' English listening and speaking ability and create a good atmosphere for English learning. Generally, the content of the platform that needs to be uploaded to the network learning platform includes multimedia resources and text materials. Multimedia resources include self-made micro lessons and courseware, micro lessons, courseware, video clips, audio materials, etc. downloaded from other learning resources websites. The teaching of the invitation letter is not complicated, and practical practice is more important than the teaching of knowledge. Therefore, there is only one micro lesson to upload multimedia resources. Text information includes guidance design, invitation letter template, invitation letter commonly used sentence pattern generalization and invitation letter. For some students with poor foundation, teachers can provide some supplementary exercises, such as inviting letters to practice.

\section{Current Problems in College English Teaching}

At present, there are many problems to be solved in College English teaching. First of all, the mode of teaching is obsolete. Most of the College English teaching still uses the traditional teaching method, and does not put students in the main position of the teaching. This restricts the students' creativity and self-learning ability to a great extent, and is also not conducive to the cultivation of students' interest in learning. Secondly, there is no change in the form of classroom teaching activities, which cannot arouse the enthusiasm and initiative of the students. College English public classes are usually closed classes or large classes, so the development of classroom activities is limited by time and space. Most of the classroom activities are carried out in the form of teacher questions and group exercises.

The limited form of activity is not only unable to achieve the purpose of the targeted practice, but also cannot help the teachers get effective and accurate feedback. Thirdly, the level of English teachers needs to be improved. There is a widespread problem in College English class. This makes it difficult for teachers to get opportunities for further study and training. Therefore, some advanced teaching ideas and methods cannot be applied to the practice of teaching for the first time.

\section{The Practical Significance of the "flipped class" Teaching Model Based on Micro Class}

Micro class is a new type of teaching based on the Internet, which is very important in the educational circles both at home and abroad. Teachers use professional software to produce videos that will be used by students according to the contents and objectives of the teaching. The main features of the micro class are flexible, small, clear teaching objectives and clear knowledge. The students watch the video micro class teaching content can be formulated by learning to download or 
online, without time and space constraints, and can repeatedly watch, decide the pace of learning, and then access or consolidation of memory. In the production of micro class, teachers should highlight the emphasis and difficulties of teaching, and use modern technical means to enrich and vivid teaching content as much as possible. In view of some practical teaching contents, teachers can also take videos that record the drill operation process, so as to directly and vividly introduce knowledge to students.

The maturity of the micro - class technology makes the teaching idea of the "flipped class" very feasible. The flipped classroom breaks the limitation of traditional classroom teaching, and gives students the initiative and autonomy of learning, which leads the progress and direction of teaching. The "flipped class" teaching mode based on micro courses will make teaching time flexible and maneuverable, and the direction of teaching becomes multidimensional and can respond to the needs of students. Under the class, the students can choose the learning time according to their own conditions, and through the way of watching the micro class, they can complete the study of the specified teaching content.

In class, teachers answer and guide students' problems and doubts in their autonomous learning, and guide students to expand their thinking and share their learning experience and experience, so as to achieve the goal of optimizing teaching effect and expanding teaching contents. "Flipped classroom" is not only conducive to training and exercising students' independent learning and thinking ability, but also developing the potential of knowledge, exploration and innovation to a large extent. As an important carrier of the "flipped class" teaching model, the quality of the micro class directly determines the quality of the teaching effect. Only the full content, exquisite and concise and concise teaching micro class can guarantee the smooth development of the "flipped class" teaching mode in the course and in the class.

\section{Acknowledgements}

Chinese society of medical education of Chinese Medical Association, Medical education Specialized Committee of China Association of Higher Education medical education research project No. 2016B-FF054.

\section{References}

[1] S.Q.G, B.Y. The micro class "convergent evolution" teaching design to promote the study of flipped classroom teaching strategies of [J]. Chinese audio-visual education, 2014 (4).

[2] Q.N.H, H.G.B. Beyond Reductionism: concept, type and development of micro class [J]. audio visual education research under the background of online education, 2014 (7).

[3] X.P.H, X.J. The construction and application of micro class resources of [J]. China education information, 2014 (9).

[4] J.H.L. Micro teaching method of the course and the localization of action China [J]. flipped classroom China education information, 2014 (14).

[5] Y.L. Collaborative learning in general teaching in the application of [J]. education review, 2014 (7).

[6] R.L, H.Y.W. The micro class "flipped classroom teaching mode design and practice of [J]. based on the modern education technology, 2014 (5). 